\title{
The Reengineering of IUPUI's Organizational Leadership and Supervision Program: Lessons Learned Along the Way
}

\author{
R. Andrew Schaffer, Clifford R. Goodwin \\ IUPUI
}

\begin{abstract}
The purpose of this paper is to initiate a discussion on applied management education within engineering technology. By presenting what we perceive to be the answers to several curriculum questions, the paper and session can help pave the way for other engineering technology educators interested in developing similar programs. Other colleges may wish to develop similar plans of study, or they may wish to incorporate some of our ideas into existing engineering management curricula.
\end{abstract}

\section{Introduction}

The Department of Organizational Leadership and Supervision (OLS), in the Purdue School of Engineering and Technology at IUPUI, offers a practical, hands-on approach to leadership development for students desiring leadership roles within any size/type of organization. A large percentage of OLS graduates move into leadership roles in manufacturing or electrical, mechanical or computer technology. To the end of serving those students and the industries where they will ultimately be employed, the OLS program blends a hands-on applied management curriculum with a traditional technology education.

\section{The new program}

For the past year the authors have been reengineering the OLS undergraduate degree programs (A.S. and B.S.) with the goal of launching a more narrowly focused, stringent, and industry-relevant OLS curriculum. The overall goals were to:

- $\quad$ Strengthen the marketability of both the A.S. and B.S. degrees

- $\quad$ Blend applied management and technical skills in a unique package

- $\quad$ Require core applied management classes that would be perceived as valuable in a variety of technical industries and settings

- $\quad$ Develop a program that offers students numerous course choices, while maintaining a high quality and consistency across graduates

This paper introduces and answers the following questions: 
- What is Organizational Leadership and Supervision (OLS) and how does OLS differ from engineering management?

- How is applied management blended with engineering technology?

- Why is OLS housed within a school of engineering and technology?

- Given the flexibility of the degree, how do students construct their plan of study?

The purpose of this paper is to initiate a discussion on applied management education within engineering technology. By presenting what we perceive to be the answers to the above questions, this paper can help pave the way for other engineering technology educators interested in developing similar programs. Other colleges may wish to develop similar plans of study, or they may wish to incorporate some of our ideas into existing engineering management curricula.

What is Organizational Leadership and Supervision (OLS) and how does OLS differ from engineering management?

The OLS program is unique in that it offers many course choices and flexibility to its students. Most engineering management and engineering technology management programs require a core set of engineering or technology courses to provide the basics of the discipline. Those degrees then add traditional business management courses such as accounting, finance, and economics. There are usually few, if any, elective choices for students in these programs. On the other hand, OLS students can and do specialize in a variety of technical specialties and also focus their applied management studies in a variety of ways.

How is applied management blended with engineering technology?

A key attribute of the OLS degree is its "three-thirds" approach to the overall education and development of its students. OLS students take about one-third of their courses in leadership and supervision, another one-third in a traditional technical discipline, and a final one-third in general education courses in the areas of math, science, english, communications, behavioral and social science and humanities. In each of these areas, there are required courses, but students also have tremendous flexibility to develop their plan of study to fit personal interests and career goals. The OLS and technology components of the new OLS B.S. degree program are outlined throughout the rest of the paper.

The OLS core consists of 43 credit hours, 28 of which are required courses:

OLS $100 \quad$ Introduction to OLS

OLS 252 Human Behavior in Organizations

OLS 263 Ethical Decisions in Leadership

OLS $274 \quad$ Applied Leadership 
OLS 327 Leadership for a Global Work Force

OLS 331 Occupational Safety and Health

OLS 378 Labor Relations

OLS 390 Leadership: Theories and Processes

OLS $410 \quad$ Survival Skills in Organizational Careers

OLS $490 \quad$ Senior Research Project

This core consists of skill and knowledge areas identified by both management research and practitioner feedback as vital and relevant for entry-level managers in a variety of industrial settings. As you will notice, these are very applied and hands-on topics, quite different from the theoretical and functional approach taken by traditional business schools (i.e., a mix of accounting, finance, human resources, economics, strategy, marketing, etc.).

For the remaining 15 hours in OLS, students choose from the following:

OLS 110 Supervisory Leadership: Story Problems (Web-based)

OLS $328 \quad$ Introduction to International Management

OLS 368 Personnel Law

OLS 373 Case Studies in Leadership

OLS 375 Training Methods

OLS 377 Project Management

OLS 383 Human Resource Management

OLS 399 Special Research Topics

OLS 454 Gender and Diversity in Management

OLS 476 Compensation Planning and Management

OLS 479 Staffing Organizations

OLS $487 \quad$ Leadership Philosophy

Students build their set of selective courses to match personal career interests. These skills complement the core skills developed in the 43 required hours. For example, students who desire a career in human resource (HR) management may earn a certificate in HR by completing OLS 368, 375, 383, 476, and 479. This 15-hour set of courses rounds out the OLS credit requirement and provides a solid HR focus that prepares students to sit for the relevant certifying exam - the "Professional in Human Resources" (PHR).

However, not all OLS students desire an HR career. For students desiring a line management position in a technology setting, a potential set of selective courses would be OLS 328, 373, 375, 377, and 487. This set of 15 credit hours allows students to consider cases and perform project work with a line management focus, compared to the staff oriented focus of the HR courses.

Why is OLS housed within a school of engineering and technology? 
The second one-third of the OLS degree builds on traditional technology courses. Students must choose up to 21 credit hours in applied technology that complement OLS and directly relate to specific career interests. In addition, students have 11 hours of free electives that may be used for related technology courses. At least 18 related technology credit hours must be a set of courses from construction technology, computer technology, electrical engineering technology, or mechanical engineering technology. These courses must be related to a second degree, a minor, a certificate, or reflect some logical combination of courses.

Along with the OLS academic counselor, students also develop a relationship with an academic counselor from the appropriate technology department and work with that counselor to earn the A.S., certificate, or minor in that discipline. In this way, students keep abreast of career opportunities and the latest information from both disciplines. At present, students may earn any one of the following technical credentials and apply that credential to their related technology requirement:

From Construction Technology: A.S. in Interior Design, or Certificates in Construction Drafting, Construction Management, or Surveying

From Computer Technology: Minor in Computer Technology or Certificate in Information Technology

From Electrical Engineering Technology: Minor in EET or Certificate in Clinical Laboratory Equipment Technology or a concentration in Bio-Medical Electrical Technology

From Mechanical Engineering Technology: Certificates in Electronics Manufacturing, Quality Control, Manufacturing Systems, Computer Graphics, or CAD/CAM

To provide an example, assume an OLS major desires an entry-level management position in the construction industry. That student would earn the B.S. in OLS with a certificate in construction management to satisfy the technical core requirement. The student would also take OLS selective classes relevant to a line manager instead of the staff-oriented HR courses. Along with OLS requirements, the student would take the following courses to earn the construction management certificate:

ART 165 Building Material and Systems

CNT 280 Quantity Survey

CNT 330 Construction Field Operations

CNT 341 Construction Scheduling and Project Control

CNT 342 Construction Cost and Bidding

CNT 347 Construction Contract Administration

CNT 447 Construction Project Management

CNT Approved Elective 
In the general education category, students would take required courses in algebra, trigonometry, statistics, engineering economics, English, speech, and technical communications. They would also take selective courses in the behavioral and social sciences and humanities. This is just one example relevant to construction management. Similar plans of study are available for each of the certificates and minors presented earlier.

Given the flexibility of the degree, how do students construct their plan of study?

One of the on-going strengths of the OLS department is the accessibility of the full-time faculty to provide student counseling. The counseling aspect has been strengthened in the new program with the addition of OLS 100, the introductory course in OLS. Students in OLS 100 will, among other things, take and be debriefed on the "Strong Campbell Interest Inventory." This instrument helps individuals define personal interests and career goals. With that knowledge in hand, students will better define their leadership interests (i.e., line or staff) and a technical area where they can apply those leadership skills (i.e., construction, manufacturing, electronics, or computers). Majors in OLS will also receive orientation presentations from faculty in each of the technology departments.

In addition to intensive counseling from the OLS faculty, students in OLS 100 are required to meet with at least two advisors from technology areas. These referrals for counseling will be based on interest areas identified in the Strong Campbell inventory. With all of this testing and counseling behind them, new OLS majors will submit for final approval their plan of study for the OLS degree. This plan of study, in effect, is multidisciplinary. It will afford students a collection of knowledge and skills that will allow them to build a strong set of complementary and highly marketable competencies.

\section{Conclusion}

Our program blends managerial skills and technology in a way that prepares students to lead. Students majoring in engineering and technology programs can benefit from taking these courses. ABET criteria for outcomes assessment stresses the need for these skills in their disciplines.

\section{R. ANDREW SCHAFFER}

Andy Schaffer is Assistant Professor of Organizational Leadership and Supervision at IUPUI. He received his B.S. in OLS from Purdue University in West Lafayette, Indiana after completing six years in the U.S. Air Force. Andy received his MBA from the University of Louisville while working full time as Manager of Operations Development for United Distillers, North America. He will receive his Ph.D. in Organizational Behavior and International Business from the Ohio State University in 2000.

CLIFFORD R. GOODWIN

Cliff Goodwin is Department Chair and Associate Professor of Organizational Leadership and Supervision at IUPUI. 